\title{
FAKTOR YANG BERHUBUNGAN DENGAN PEMBERIAN ASI EKSKLUSIF PADA BAYI USIA 6-12 BULAN DI WILAYAH KERJA PUSKESMAS SIGALINGGING KABUPATEN DAIRI TAHUN 2017
}

\author{
${ }^{1}$ Fitri Debby Sitohang, ${ }^{2}$ Irawaty A. Kahar, ${ }^{3}$ Asima Sirait \\ ${ }^{1,2,3}$ Program Studi Magister Ilmu Kesehatan Masyarakat Universitas Sari Mutiara Indonesia \\ Email : debitupang@yahoo.com
}

\begin{abstract}
ABSTRAK
Cakupan bayi yang diberi ASI Eksklusif secara nasional tahun 2015 sebesar 55,7\%, di Sumatera Utara tahun 2015 sebesar 33\% dan cakupan ASI Eksklusif di Wilayah kerja Puskesmas Sigalingging kabupaten Dairi sebesar 4,1\%. Penelitian ini bertujuan mengetahui faktor-faktor yang berhubungan dengan pemberian ASI Eksklusif pada bayi usia 6-12 bulan di wilayah kerja Puskesmas Sigalingging Kabupaten Dairi. Jenis penelitian ini adalah analitik observasional dengan pendekatan cross sectional study. Populasi dalam penelitian ini adalah semua ibu yang memiliki bayi usia 6-12 bulan di wilayah kerja Puskesmas Sigalingging Kabupaten Dairi sebanyak 95 orang. Sampel dalam penelitian ini adalah seluruh populasi dengan menggunakan tehnik sampel total populasi sejumlah 95 orang. Analisis data melaui tahapan analisis univariat, analisis bivariat dengan uji chi square dan analisis regresi logistik berganda. Hasil penelitian menunjukan bahwa ada hubungan pengetahuan dengan pemberian ASI Eksklusif, ada hubungan dukungan suami dengan pemberian ASI Eksklusif, ada hubungan persiapan fisik dan mental dengan pemberian ASI Eksklusif, ada hubungan dukungan petugas kesehatan dengan pemberian ASI Eksklusif, ada hubungan sosial budaya dengan pemberian ASI Eksklusif. Disarankan kepada Puskesmas Sigalingging agar membuat program penyuluhan ASI Eksklusif kepada ibu hamil dan suaminya.
\end{abstract}

Kata kunci : Faktor yang brhubungan, ASI Eksklusif, Bayi Usia 6-12 bulan.

\section{PENDAHULUAN}

Menyusui meski terdengar sederhana tapi pelaksanaannya sangat sulit. Banyak sekali penghambat keberhasilan ASI Eksklusif. Rendahnya pemberian air susu ibu (ASI) merupakan ancaman bagi tumbuh kembang anak, dan masalah pemberian ASI Eksklusif pada bayi ini sangat memprihatinkan dan tanpa disadari mengakibatkan dampak yang fatal bagi masa depan anak (Maryunani,2012).

Meskipun Pemerintah sudah mencanangkan pemberian ASI eksklusif selam 6 bulan dan melanjutkan sampai usia 2 tahun yang termuat dalam Undangundang No.36 tahun 2009 tentang kesehatan, PP No.33 tahun 2013 tentang ASI Eksklusif, namun capaian ASI Eksklusif belum mencapai target (Labbok, MH,2013).

Organisasi Kesehatan Dunia (WHO) dan UNICEF merekomendasikan menyusui eksklusif (exsclusive breastfeeding) sejak lahir selama 6 bulan pertama hidup anak dan tetap disusui bersama pemberian makanan pendamping ASI (MP-ASI) yang cukup sampai usia 2 tahun atau lebih. Pemberian ASI secara eksklusif merupakan salah satu upaya menurunkan angka kesakitan, kematian pada bayi dan balita, disamping itu pemberian ASI eksklusif juga dapat mengurangi resiko penyakit akut dan kronis termasuk diare, penyakit infeksi saluran pernafasan, infeksi saluran kemih, otitis media dan asma (Depkes,2011).

Ada banyak faktor yang menyebabkan kegagalan ASI Eksklusif, salah satunya adalah hasil penelitian Devi dkk (2014) dimana faktor yang mempengaruhi kegagalan pemberian ASI Eksklusif adalah faktor psikis dan sosial budaya. Kebiasaan keluarga maupun lingkungan sekitar memberikan hubungan yang sangat signifikan dalam pengambilan keputusan ibu untuk memberikan ASI Eksklusif. Sementara dalam jurnal Abd. Rahman (2015) terdapat hubungan yang bermakana antara pengetahuan, sikap dan dukungan suami dengan praktek pemberian ASI Eksklusif. Semakin tinggi dukungan suami dalam pemberian ASI Eksklusif dengan 
didukung oleh suami maka semakin tinggi kepercayaan ibu untuk memutuskan memberikan ASI Eksklusif.

Cakupan pemberian ASI eksklusif di kabupaten Dairi tahun 2013 sebesar $40 \%$ dan tahun 2014 sebesar $11,9 \%$, tahun 2015 sebesar 42,7\%. Sementara tahun 2014 Puskesmas Sigalingging 2,3\%, tahun 2015 sebesar 4,1\%. Dan di Puskesmas Sigalingging merupakan capaian paling sedikit dalam cakupan pemberian ASI eksklusif yaitu $4,1 \%$.

Berdasarkan pengamatan awal di posyandu Lae hole, petugas Kesehatan menjelaskan bahwa dari 25 orang ibu yang memiliki bayi $0-6$ bulan hanya $10 \%$ yang memberikan ASI Eksklusif sedangkan yang $90 \%$ tidak memberikan ASI Eksklusif. seorang ibu mengemukakan bahwa pemberian ASI Eksklusif adalah pemberian ASI yang diberikan harus didampingi dengan bubur ataupun susu dengan tujuan agar bayi cepat besar. Kebiasaan dan tradisi ini sudah turun temurun dilakukan dengan tujuan agar bayi cepat besar. Salah seorang ibu yang lain juga mengatakan bahwa semenjak dia melahirkan, tenaga kesehatan langsung menawarkan pemberian susu formula dengan alasan air susu ibu belum keluar, ditambah dengan kurangnya dukungan suami yang menganjurkan agar bayi diberi susu formula agar ibu tidak terganggu bekerja. Hal tersebutlah menjadi awal bayi tidak diberi ASI secara eksklusif. Tujuan umum penelitian ini adalah untuk mengetahui faktor - faktor yang berhubungan dengan pemberian ASI Eksklusif di wilayah kerja Puskesmas Sigalingging Kabupaten Dairi tahun 2017.

\section{METODE}

Jenis penelitian ini merupakan penelitian deskriptif analitik dengan pendekatan sekat lintang (cross sectional study) yang bertujuan untuk menganalisis faktor -faktor yang berhubungan dengan Pemberian ASI Ekslusif pada bayi usia 612 bulan di Wilayah Kerja Puskesmas Sigalingging Kabupaten Dairi. Lokasi penelitian di Puskesmas Sigalingging Kabupaten Dairi dengan pertimbangan hasil capaian ASI Ekslusif masih rendah yakni hanya $4,1 \%$. Sampel dalam penelitian ini adalah seluruh populasi dengan menggunakan metode pengambilan sampel dengan tehnik sampel total populasi sebanyak 95 orang. Metode Pengumpulan Data melalui Data primer yakni data yang diiperoleh dari jawaban responden pada kuesioner penelitian yang telah disusun dan mengacu kepada variabel yang diteliti. Data sekunder yakni data yang diperoleh dari literatur, buku buku referensi, dan jurnal penelitian.

\section{HASIL}

\section{Analisis Univariat}

Analisis univariat dalam penelitian ini meliputi : umur, pendidikan, pengetahuan, dukungan suami, dukungan petugas kesehatan, persiapan fisik dan mental, sosial budaya dan pemberian ASI Eksklusif.

Tabel 1. Distribusi Frekuensi Umur

\begin{tabular}{cccc}
\hline No & Umur $($ tahun) & f & \% \\
\hline 1 & $>30$ tahun & 59 & 62 \\
\hline 2 & $<30$ tahun & 36 & 38 \\
\hline
\end{tabular}

Pada Tabel 1 tersebut di atas dapat diketahui bahwa kelompok umur > 30 tahun mayoritas yangmemberikan ASI Eksklusif.

Tabel 2. Distribusi Frekuensi Pendidikan

\begin{tabular}{clcc}
\hline No & Pendidikan & f & \% \\
\hline 1 & SD & 41 & 43 \\
\hline 2 & SLTP & 11 & 12 \\
\hline 3 & SMA & 33 & 35 \\
\hline 4 & Perguruan Tinggi & 10 & 11 \\
\hline
\end{tabular}

Tabel 2 di atas dapat diketahui bahwa pendidikan SD adalah mayoritas pendidikan ibu.

Tabel 3. Distribusi Frekuensi Pendidikan

\begin{tabular}{clcc}
\hline No & Pendidikan & f & \% \\
\hline 1 & SD & 41 & 43 \\
\hline 2 & SLTP & 11 & 12 \\
\hline 3 & SMA & 33 & 35 \\
\hline 4 & Perguruan Tinggi & 10 & 11 \\
\hline
\end{tabular}

Berdasarkan Tabel 3 di atas dapat diketahui bahwa pengetahuan kurang baik adalah mayoritas pengetahuan ibu.

Tabel 4. Distribusi Frekuensi Dukungan Suami

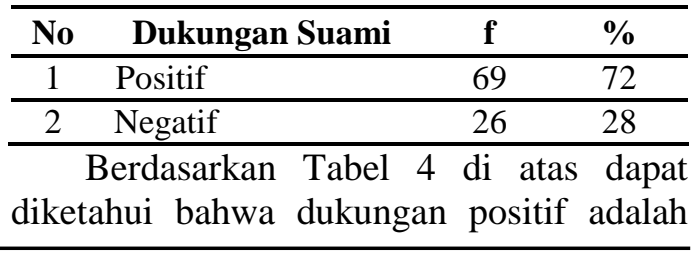


mayoritas dukungan suami dalam pemberian ASI Eksklusif.

Tabel 5. Distribusi Frekuensi Dukungan Petugas Kesehatan

\begin{tabular}{|c|c|c|c|}
\hline No & Dukungan Petugas Kesehatan & f & $\%$ \\
\hline 1 & Positif & 49 & 49 \\
\hline 2 & Negatif & 46 & 46 \\
\hline
\end{tabular}
diketahui bahwa dukungan positif adalah mayoritas dukungan petugas kesehatan dalam memberikan ASI Eksklusif.

Tabel 6. Distribusi Frekuensi Persiapan Fisik dan Mental

\begin{tabular}{|c|c|c|c|}
\hline No & Persiapan Fisik dan Mental & $\mathbf{f}$ & $\%$ \\
\hline 1 & Ada & 52 & $\overline{55}$ \\
\hline 2 & Tidak ada & 43 & 45 \\
\hline
\end{tabular}

diketahui bahwa adanya persiapan fisik dan mental adalah mayoritas persiapan fisik dan mental ibu dalam memberikan ASI Eksklusif.

Tabel 7. Distribusi FrekuensiSosial Budaya

\begin{tabular}{|c|c|c|c|}
\hline No & Sosial Budaya & f & $\%$ \\
\hline 1 & Mendukung & 64 & 68 \\
\hline 2 & Kurang mendukung & 31 & 32 \\
\hline
\end{tabular}
diketahui bahwa sosial budaya yang baik adalah mayoritas sosial budaya ibu dalam pemberian ASI Eksklusif.

Tabel 8. Distribusi Frekuensi Pemberian ASI Eksklusif

\begin{tabular}{llll}
\hline No & $\begin{array}{c}\text { Pemberian ASI } \\
\text { Eksklusif }\end{array}$ & f & \% \\
\hline 1 & Ya & 36 & 38 \\
\hline 2 & Tidak & 59 & 62 \\
\hline
\end{tabular}

Berdasarkan Tabel 8 di atas dapat diketahui bahwa tidak memberikan ASI Eksklusif adalah mayoritas ibu dalam memberikan ASI Eksklusif.

\section{Analisis Bivariat}

Analisis ini berfungsi untuk mengidentifikasi hubungan variabel faktor pengetahuan, dukungan suami, dukungan petugas kesehatan, persiapan fisik dan mental, sosial budaya terhadap pemberian ASI Eksklusif di Kabupaten Dairi.

Tabel 9. Hubungan Pengetahuan Dengan Pemberian ASI Eksklusif

\begin{tabular}{|c|c|c|c|c|c|c|c|c|}
\hline \multirow{3}{*}{ Pengetahuan } & \multicolumn{4}{|c|}{ Pemberian ASI Eksklusif } & \multirow{2}{*}{\multicolumn{2}{|c|}{ Total }} & \multirow{3}{*}{$p$-value } & \multirow{3}{*}{ OR } \\
\hline & \multicolumn{2}{|c|}{ Ya } & \multicolumn{2}{|c|}{ Tidak } & & & & \\
\hline & $\mathbf{F}$ & $\%$ & $\mathbf{f}$ & $\%$ & $\mathbf{f}$ & $\%$ & & \\
\hline Baik & 30 & 77 & 9 & 23 & 39 & 41 & 0,000 & 0,36 \\
\hline Kurang Baik & 6 & 11 & 50 & 89 & 56 & 59 & 0,000 & 0,36 \\
\hline
\end{tabular}

Berdasarkan Tabel 9 di atas dapat diketahui bahwa dari 39 ibu yang berpengetahuan baik, hanya $30(77 \%)$ ibu yang memberikan ASI Eksklusif. Sedangkan dari 56 ibu yang berpengetahuan kurang baik, hanya $6(11 \%)$ ibu yang memberikan ASI Eksklusif. Hasil statistik menunjukan nilai ( $p$-value $=0,000$ ) dapat diartikan terdapat hubungan yang signifikan antara pengetahuan ibu dengan pemberian ASI Eksklusif di wilayah kerja Puskesmas Sigalingging Kabupaten Dairi Hasil statistik juga menunjukan nilai $(\mathrm{OR}=$ 0,36 ) dapat diartikan bahwa ada hubungan pengetahuan baik sebesar 0,36 dengan pemberian ASI Eksklusif dibandingkan pengetahuan kurang baik di wilayah kerja Puskesmas Sigalingging Kabupaten Dairi.

Tabel 10. Hubungan Dukungan Suami Dengan Pemberian ASI Eksklusif

\begin{tabular}{|c|c|c|c|c|c|c|c|c|}
\hline \multirow{3}{*}{$\begin{array}{c}\text { Dukungan } \\
\text { Suami }\end{array}$} & \multicolumn{4}{|c|}{ Pemberian ASI Eksklusif } & \multirow{2}{*}{\multicolumn{2}{|c|}{ Total }} & \multirow{3}{*}{$p$-value } & \multirow{3}{*}{ OR } \\
\hline & \multicolumn{2}{|c|}{ Ya } & \multicolumn{2}{|c|}{ Tidak } & & & & \\
\hline & $\mathbf{F}$ & $\%$ & f & $\%$ & f & $\%$ & & \\
\hline Positif & 17 & 25 & 52 & 75 & 69 & 72 & 0,000 & 8,303 \\
\hline Negatif & 19 & 73 & 7 & 27 & 26 & 23 & 0,000 & 8,303 \\
\hline
\end{tabular}

Berdasarkan Tabel 10 di atas dapat diketahui bahwa dari 69 suami yang memberikan dukungan positif,terdapat $17(25 \%)$ ibu yang memberikan ASI Eksklusif. Sedangkan dari 26 suami yang memberikan dukungan negatif, terdapat 19
(73\%) ibu memberikan ASI Eksklusif. Hasil uji statistik menunjukan $\operatorname{nilai}(p=$ $0,000 ; \alpha=0,005)$, sehingga dapat diartikan bahwa terdapat hubungan yang signifikan antara dukungan suami dengan pemberian ASI Eksklusif di wilayah kerja Puskesmas 
Sigalingging Kabupaten Dairi. Hasil statistik juga menunjukan nilai $(\mathrm{OR}=$ 8,303 ) dapat diartikan bahwa ada hubungan dukungan positif suami sebesar 8,303 dengan pemberian ASI Eksklusif dibandingkan dukungan negatif suami di wilayah kerja Puskesmas Sigalingging Kabupaten Dairi.

Tabel 11. Hubungan Persiapan Fisik dan Mental Dengan Pemberian ASI Eksklusif

\begin{tabular}{|c|c|c|c|c|c|c|c|c|}
\hline \multirow{3}{*}{$\begin{array}{c}\text { Persiapan Fisik } \\
\text { dan Mental }\end{array}$} & \multicolumn{4}{|c|}{ Pemberian ASI Eksklusif } & \multirow{2}{*}{\multicolumn{2}{|c|}{ Total }} & \multirow{3}{*}{ p-value } & \multirow{3}{*}{$\mathbf{O R}$} \\
\hline & \multicolumn{2}{|c|}{$\mathbf{Y a}$} & \multicolumn{2}{|c|}{ Tidak } & & & & \\
\hline & $\mathbf{F}$ & $\%$ & $\mathbf{f}$ & $\%$ & $\mathbf{f}$ & $\%$ & & \\
\hline Ada & 12 & 23 & 40 & 77 & 52 & 54 & 0,002 & \\
\hline Tidak ada & 24 & 56 & 19 & 44 & 43 & 45 & & 4,2 \\
\hline
\end{tabular}

Berdasarkan Tabel 11 di atas dapat diketahui bahwa dari 52 ibu yang memiliki persiapan fisik dan mental terdapat 12 $(23 \%) \%$ ) ibu yang memberikan ASI Eksklusif sedangkan dari 43 ibu yang tidak ada persiapan fisik dan mental terdapat 24(56\%) ibu yang memberikan ASI Eksklusif. Hasil statistik menunjukan bahwa nilai ( $p=0,002 ; \alpha=0,005)$ sehingga dapat diartikan bahwa terdapat hubungan yang signifikan antara persiapan fisik dan

mental dengan pemberian ASI Eksklusif di wilayah kerja Puskesmas Sigalingging Kabupaten Dairi. Hasil statistik juga menunjukan nilai $(\mathrm{OR}=4,211)$ yang artinya bahwa ada hubungan persiapan fisik dan mental ibu sebesar 4,211 dengan pemberian ASI Eksklusif dibandingkan ibu yang tidak memiliki persiapan fisik dan mental dengan pemberian ASI Eksklusif di wilayah kerja Puskesmas Sigalingging Kabupaten Dairi.

Tabel 12. Hubungan Dukungan Petugas Kesehatan Dengan Pemberian ASI Eksklusif

\begin{tabular}{|c|c|c|c|c|c|c|c|c|}
\hline \multirow{3}{*}{$\begin{array}{c}\text { Dukungan Petugas } \\
\text { Kesehatan }\end{array}$} & \multicolumn{4}{|c|}{ Pemberian ASI Eksklusif } & \multirow{2}{*}{\multicolumn{2}{|c|}{ Total }} & \multirow{3}{*}{$p$-value } & \multirow{3}{*}{$\mathbf{O R}$} \\
\hline & \multicolumn{2}{|c|}{ Ya } & \multicolumn{2}{|c|}{ Tidak } & & & & \\
\hline & $\mathbf{f}$ & $\%$ & $\mathbf{f}$ & $\%$ & f & $\%$ & & \\
\hline Positif & 11 & 22 & 38 & 78 & 49 & 52 & 0.003 & 4.113 \\
\hline Negatif & 25 & 54 & 21 & 45 & 46 & 48 & & \\
\hline
\end{tabular}

Berdasarkan Tabel 12 dapat diketahui kesehatan dengan pemberian ASI Eksklusif bahwa dari 49 petugas kesehatan yang memberikan dukungan positif terdapat $11(22 \%)$ ibu yang memberikan ASI Eksklusif. Sedangkan dari 46 petugas kesehatan yang memberikan dukungan negatif terdapat 25(54\%) ibu yang memberikan ASI Eksklusif. Hasil statistik menunjukan nilai $(p=0,003 ; \alpha=0,005)$ dapat diartikan bahwa terdapat hubungan yang signifikan antara dukungan petugas di wilayah kerja Puskesmas Sigalingging Kabupaten. Hasil statistik juga menunjukan nilai $(\mathrm{OR}=4,113)$ yang artinya bahwa ada hubungan dukungan positif petugas kesehatan sebesar 4,113 dengan pemberian ASI Eksklusif dibandingkan dengan dukungan negatif petugas kesehatan dengan pemberian ASI Eksklusif di wilayah kerja Puskesmas Sigalingging Kabupaten Dairi.

Tabel 13. Hubungan Sosial Budaya Dengan Pemberian ASI Eksklusif

\begin{tabular}{|c|c|c|c|c|c|c|c|c|}
\hline \multirow{3}{*}{ Sosial Budaya } & \multicolumn{4}{|c|}{ Pemberian ASI Eksklusif } & \multirow{2}{*}{\multicolumn{2}{|c|}{ Total }} & \multirow{3}{*}{ p-value } & \multirow{3}{*}{ OR } \\
\hline & \multicolumn{2}{|c|}{$\mathbf{Y a}$} & \multicolumn{2}{|c|}{ Tidak } & & & & \\
\hline & $\mathbf{f}$ & $\%$ & $\mathbf{F}$ & $\%$ & $\mathbf{f}$ & $\%$ & & \\
\hline Mendukung & 19 & 29 & 45 & 70 & 64 & 53 & 0,032 & 2,876 \\
\hline Tidak mendukung & 17 & 54 & 14 & 45 & 31 & 47 & & \\
\hline
\end{tabular}

Berdasarkan Tabel 13 dapat diartikan bahwa dari $64 \mathrm{ibu}$ dengan sosial budaya yang mendukung terdapat 19 (29\%) ibu yang memberikan ASI Eksklusif. Sedangkan dari 31 ibu dengan sosial budaya yang tidak mendukung terdapat 17 (54\%) ibu yang memberikan ASI Eksklusif.Hasil statistik menunjukan nilai $(p$ $=0,016 ; \alpha=0,005)$ dapat diartikan terdapat hubungan yang signifikan sosial budaya ibu dengan pemberian ASI Eksklusif di wilayah kerja Puskesmas Sigalingging Kabupaten Dairi. Hasil statistik juga menunjukan nilai $(\mathrm{OR}=2,876)$ ada hubungan sosial budaya yang mendukung pemberian ASI Eksklusif sebesar 2,876 dibandingkan dengan sosial budaya yang tidak mendukung pemberian 
ASI Eksklusif di wilayah kerja Puskesmas Sigalingging Kabupaten Dairi.

\section{PEMBAHASAN}

\section{Hubungan Pengetahuan Dengan Pemberian ASI Eksklusif di Wilayah Kerja Puskesmas Sigalingging Kabupaten Dairi}

Dari hasil penelitian terdapat $39 \mathrm{ibu}$ dengan pengetahuan yang baik dan $56 \mathrm{ibu}$ dengan pengetahuan yang kurang baik. Dari 39 ibu yang berpengetahuan baik, hanya $30(77 \%)$ ibu yang memberikan ASI Eksklusif. Sedangkan dari 56 ibu yang berpengetahuan kurang baik terdapat 6 $(11 \%)$ ibu yang memberikan ASI Eksklusif. Hal ini dapat dilihat dari hasil jawaban kuesioner responden dari pernyataan I sampai 10 tercatat sebanyak 50 ibu menjawab benar bahwa ASI yang pertama kali keluar baik untuk diberikan kepada bayi, 59 ibu menjawab benar pernyataan memberikan ASI kepada bayi jauh lebih murah dan efektif dibandingkan dengan susu formula, 67 ibu menjawab benar pernyataan ASI sangat baik diberikan kepada bayi, $58 \mathrm{ibu}$ menjawab benar ASI saja selama 6 bulan pertama sudah mencukupi kebutuhan bayi, 35 ibu menjawab benar pernyataan ASI tidak cukup membuat bayi cepat besar dan kuat, sehingga perlu diberi makanan tambahan sebelum usia 6 bulan, 50 ibu menjawab pernyataan menyusui membuat payudara kendur dan tidak bagus lagi, $51 \mathrm{ibu}$ menjawab pernyataan menyusui membuat ibu semakin gemuk, 69 ibu menjawab pernyataan bayi harus diberikan makanan tambahan agar bayi tidak selalu menangis, 70 ibu menjawab pernyataan ASI saja tidak cukup diberikan kepada bayi karena kandungan gizinya belum memenuhi kebutuhan bayi

Menurut asumsi peneliti upaya peningkatan tersebut dapat melalui pemberian informasi yang benar oleh petugas kesehatan kepada para ibu hamil ketika ibu hamil datang ke puskesmas melakukan pemeriksaan kehamilan. Pemberian leaflet tentang informasi kesehatan, informasi gizi yang dibutuhkan ibu dan bayi pada masa kehamilan dan setelah melahirkan. Dibukanya kelas ibu hamil dengan mengundang dokter spesialis atau nara sumber yang memberikan penyuluhan mengenai pentingnya ASI Eksklusif pada bayi. Pemberian informasi pertama sekali diberikan kepada kader baik berupa penyuluhan atau pelatuhan mengenai ASI Eksklusif. Peningkatan pengetahuan ASI Eksklusif kepada kader sebagai perpanjangan tangan antara petugas dan masyarakat, sehinggan kader dapat memberikan Informasi yang benar. Membuat spanduk atau poster ASI Eksklusif di sekitar jalan yang dilewati masyarakat. Mengundang para tokoh masyarakat, tokoh agama dan penatua adat untuk menghimbau para ibu hamil dan menyusui untuk aktif memeriksakan kehamilannya di puskesmas. Bekerjasama dengan kepala desa / camat untuk melakukan pertemuan tingkat desa dalam membahas angka penyakit pada bayi akibat rendahnya pemberian ASI Eksklusif. Dengan meningkatkan pengetahuan, diharapakan pemberian ASI Eksklusif juga meningkat. Sehingga program pemerintah tentang keluarga sehat yang salah satunya melalui pemberian ASI Eksklusif dapat tercapai meskipun secara perlahan. Mengubah mindset atau persepsi ibu akan mempengaruhi sikap dan perilaku ibu dalam memberikan ASI Eksklusif.

\section{Hubungan Dukungan Suami Dengan Pemberian ASI Eksklusif di Wilayah Kerja Puskesmas Sigalingging Kabupaten Dairi}

Dalam penelitian ini ditemukan dari 69 suami yang memberikan dukungan positif dan 26 suami yang memberikan dukungan negatif. Dari 69 dukungan suami yang bersifat positif terdapat $17(25 \%)$ ibu yang memberikan ASI Eksklusif. Sedangkan dari 26 suami yang memberikan dukungan negatif, terdapat 19 (73\%) ibu memberikan ASI Eksklusif. Dukungan positif yang diberikan suami tidak serta merta membuat ibu memberikan ASI Eksklusif. Masalah di atas didukung oleh jawaban responen dari kuesioner yang terdiri dari 10 pernyataan dimana sebanyak 52 ibu menjawab jikalau suami menyarankan agar ibu memberikan makanan pendamping seperti susu/buah buahan/bubur sebagai makanan pendamping ASI agar bayi tidak rewel, 34 ibu menjawab jikalau suami ibu melarang ibu menyusui karena takut payudara ibu kendur, 55 ibu menjawab jikalau suami ibu menganjurkan ibu berhenti menyusui 
dikarenakan takut berat badan ibu semakin bertambah gemuk, 80 ibu menjawab jikalau suami ibu menganjurkan ibu memberikan bayi susu formula agar ibu tidak terganggu mengerjakan pekerjaan rumah tangga yang lain, 55 ibu menjawab jikalau suami ibu menyarankan agar ibu memberikan bubur agar berat badan bayi naik, 37 ibu menjawab jikalau suami ibu mau menyediakan / membelikan makanan bergizi/ buah buahan/ susu untuk ibu selama ibu memberikan ASI kepada bayi, 68 ibu menjawab jikalau suami ibu mau membantu ibu dalam merawat bayi selama masa menyusui (0-6 bulan), 45 ibu menjawab jikalau suami ibu mau menjaga bayi secara bergantian, 22 ibu menjawab jikalau suami ibu mau mengerjakan pekerjaan sehari hari, seperti membersihkan rumah, mencuci, memasak dan lain sebagainya selagi ibu menyusui, 52 ibu menjawab jikalau suami ibu pernah memuji ibu karena ibu memberikan ASI kepada bayi ibu.

Menurut asumsi peneliti upaya peningkatan tersebut dapat melalui pendekatan kepada suami dengan mengubah persepsi akan pentingnya ASI Eksklusif. Salah satunya dengan meningkatkan pengetahuan pada suami tentang manfaat dan kerugian pemberian ASI Eksklusif. Dalam hal ini suami membutuhkan informasi mengenai ASI Eksklusif, dengan pengetahuan positif akan membentuk sikap positif untuk mendorong dan membantu ibu dalam menyusui, mampu menghargai serta berbagi pekerjaan rumah tangga dan pengasuhan. Perlunya pendekatan oleh petugas kesehatan kepada para suami bahwa membesarkan anak adalah tanggung jawab bersama, salah satunya adalah pemberian ASI Eksklusif. Dengan memberikan ASI Eksklusif maka para suami juga mendukung pertumbuhan yang baik pada anak anaknya. Sebaliknya dengan tidak memberikan ASI Eksklusif, berarti suami tidak memberikan hak kepada bayinya untuk mendapat gizi dan nutrisi yang sehat. Petugas kesehatan wajib menghimbau suami agar mendampingi istri saat memeriksakan kehamilan. Dengan menemani istri, suami secara tidak sadar memberikan energi positif kepada istri.

\section{Hubungan Persiapan Fisik dan Mental} Dengan Pemberian ASI Eksklusif di

\section{Wilayah Kerja Puskesmas Sigalingging} Kabupaten Dairi

Dalam penelitian ini dapat diketahui bahwa dari 52 ibu yang memiliki persiapan fisik dan mental terdapat $12(23 \%)$ ibu yang memberikan ASI Eksklusif sedangkan dari 43 ibu yang tidak ada persiapan fisik dan mental terdapat 24(56\%) ibu yang memberikan ASI Eksklusif. Hal tersebut dapat dilihat dari jawaban kuesioner responden yakni sebanyak 42 ibu melakukan perawatan payudara sebelum melahirkan, 26 ibu sering konsultasi kepada teman/petugas kesehatan / orang lain mengenai tehnik menyusui, 59 ibu merasa percaya diri untuk menyusui selama 6 bulan, 48 ibu yakin ASI ibu cukup untuk bayi, 55 ibu merasa tegang dan khawatir saat melakukan proses persalinan, $60 \mathrm{ibu}$ merasa menyusui adalah hal yang sulit, 55 ibu sudah menyiapakan susu formula untuk pendamping ASI, 76 ibu berencana untuk memberikan makan bayi sebelum bayi usia 6 bulan

Dari jawaban responden menunjukan bahwa hampir $50 \%$ ibu tidak memepersiapkan dirinya secara fisik dan mental dalam mempersiapkan ASI Eksklusif kepada bayinya, banyaknya faktor seperti kurangnya pengetahuan tentang tehnik perawatan payudara, dna minimnya konsultasi kepada tenaga kesehatan membuat ibu merasa bahwa persiapan menyusui secara eksklusif tidaklah begitu penting. Ada keyakinan mengenai penambahan susu formula dapat menggantikan nilai gizi ASI. Keyakinan akan hal yang salah secara turun temurun membudaya di lingkungan masyarakat puskesmas Sgalingging khusunya para ibu.

Hasil penelitian ini sesuai dengan hasil penelitian yang dilakukan oleh Dwi Yolanda dan Putri (2015) menunjukan terdapat hubungan persiapan mental dengan pemberian Asi Eksklusi. Kurangnya persiapan mental dapat menimbulkan masalah bagi ibu maupun bayi, salah satunya ibu tidak bisa menyusui secara eksklusif akibat ASI yang tidak keluar, dapat menimbulkan tingkat stress pada ibu. Hal ini dipengaruhi pendidikan masyarakat di wilayah puskesmas Sigalingging yang rendah, tidak ada dukungan suami/ orang terdekat menjadi pendukung rendanya ASI Eksklusif. 
Menurut asumsi peneliti upaya peningkatan persiapan fisik dan mental yang baik akan meningkatkan pemberian ASI Eksklusif. Beberapa cara yang dapat dilakukan dalam meningkatkan persiapan fisik dan mental ibu yakni dengan melakukan pendekatan pada ibu melalui kelas ibu hamil. Ibu hamil perlu diajarkan tehnik perawatan payudara selama masa kehamilan, tehnik menyusui yang baik dan benar. Makanan dan minuman yang meningkatkan produksi ASI. Persiapan mental perlu dilakukan oleh petugas kesehatan agar para ibu memiliki keyakinan mampu memproduksi ASI dan menyusi secara eksklusif mulai bayi lahir sampai usia 6 bulan. Memberikan penyuluhan kepada ibu untuk tidak stres, khawatir, pada periode menyusui sangat berperan dalam mensukseskan pemberian ASI Eksklusif ditambah dengan peran keluarga khusunya suami dalam meningkatkan kepercayaan diri ibu sangat besar. Petugas kesehatan juga harus memantau gizi ibu mulai trimester kedua karena ibu perlu mengkonsumsi kalori ekstra. Pemberian Penyuluhan harus diberikan secara kontiniu dan tidak terputus putus guna membentuk pengetahuan dan persipan ibu secara fisik dan mental dalam menghadapi kelahiran bayinya.

Hubungan Dukungan Petugas Kesehatan Dengan Pemberian ASI Eksklusif di Wilayah Kerja Puskesmas Sigalingging Kabupaten Dairi

Menurut hasil penelitian dari 49 petugas kesehatan yang memberikan dukungan positif terdapat 11(22\%) ibu yang memberikan ASI Eksklusif. Sedangkan dari 46 petugas kesehatan yang memberikan dukungan negatif terdapat $25(54 \%)$ ibu yang memberikan ASI Eksklusif. Dukungan positif yang diberikan petugas kesehatan tidak membuat ibu memberikan ASI Eksklusif kepada bayinya. Keadaan tersebut kemungkinan disebabkan bahwa dukungan yang tidak secara kontiniu dan terputus putus dan didukung oleh faktor pendidikan yang rendah, mayoritas ibu berpendidikan hanya sampai sekolah dasar (SD). Pendidikan yang rendah mengakibatkan ibu sulit menerima masukan dan informasi terkait dengan upaya yang dapat dilakukan dalam menunjang pemberian ASI Eksklusif. Hal tersebutlah yang membuat ibu tidak memberikan Asi Eksklusif. Jawaban kuesioner responden menunjukan sebanyak 54 ibu mendapatkan informasi tentang ASI dari petugas kesehatan, 56 ibu mendapatkan informasi dari petugas kesehatan mengajari cara menyusui dengan benar, 55 ibu mendapatkan informas dari petugas kesehatan memberikan informasi tentang perawatan payudara, 45 ibu mendapatkan informas dari petugas kesehatan bagaimana cara agar produksi ASI ibu banyak, $50 \mathrm{ibu}$ menjawab dengan benar jikalau petugas kesehatan menganjurkan ibu memberikan bubur pada bayi, 45 ibu dengan benar jikalau petugas kesehatan menganjurkan ibu memberikan buah buahan pada bayi, $62 \mathrm{ibu}$ menjawab dengan benar jikalau petugas kesehatan menganjurkan ibu memberikan susu formula.

Menurut asumsi peneliti untuk menyelesaikan masalah tersebut dan meningkatkan ASI Eksklusif bila ditinjau dari dukungan petugas kesehatan maka perlu peningkatan pengetahuan petugas puskesmas (tenaga pelaksana gizi/T PG) kaderdan bidan di desa dalam memantau pemberian ASI Eksklusif, pengamatan situasi/latar belakang masalah sosial budaya setempat yang menyebabkan kegagalan ASI Eksklusif di daerah tersebut, menggali informasi dari para tenaga kesehatan tentang masalah pemberian ASI yang mereka ketahui dilapangan, melakukan persamaan persepsi tentang cara menyusui yang baik dan benar, pentingnya kolostrum bagi kesehatan bayi dan bahayanya memberikan makanan pralakteal bagi bayi persamaan persepsi tentang indikator dan pemantauan ASI Eksklusif terus menerus.

\section{Hubungan Sosial Budaya Terhadap Dengan Pemberian ASI Eksklusif di Wilayah Kerja Puskesmas Sigalingging Kabupaten Dairi}

Menurut hasil penelitian dari $64 \mathrm{ibu}$ dengan sosial budaya yang baik terdapat $19(29 \%)$ ibu yang memberikan ASI Eksklusif. Sedangkan dari 31 ibu dengan sosial budaya yang kurang baik terdapat 17 (54\%) ibu yang memberikan ASI Eksklusif.

Menurut asumsi peneliti upaya peningkatan pemberian ASI Eksklusif melalui sosial budaya dapat dimulai dengan memperbaiki budaya yang salah dalam 
memberikan nutrisi pada bayi usia 0-6 bulan, yakni perlunya dukungan keluarga baik suami, orang tua/mertua, dukun, dan masyarakat lainnya agar ibu memberikan ASI secara Eksklusi pada bayinya sampai usia 6 bulan. Petugas kesehatan hendaknya dapat menggali adanya sosial budaya yaitu kebiasaan dan kepercayaan yang ada dalam masyarakat tersebut melalui pendekatan kepada tokoh agama, tokoh masyarakat, dukun bersalin, dan masyarakat lainnya sehingga dapat membantu terlaksananya pemberian ASI secara Eksklusi pada bayi.

Sosial budaya yang baik hendaknya dapat dipertahankan dengan memotivasi masyarakat untuk selalu melaksanakan kebiasaan tersebut dan sosial budaya yang kurang dan tidak mendukung hendaknya dapat diberikan pemahaman kepada ibu dan masyarakat tentang keuntungan dan kerugian dari perilaku tersebut dengan cara memberikan penyuluhan, pembinaan, pelatihan keterampilan cara perawatan bayi yang baik pada masyarakat baik melalui pertemuan kelompok, kunjungan rumah, dan melakukan pendekatan pada tokoh agama dan tokoh masyarakat sesuai dengan permasalahan yang ada, sehingga dengan kesadaran sendiri masyarakat dapat merubah kebiasaan tersebut ke arah yang lebih baik.

\section{KESIMPULAN}

1. Terdapat hubungan yang signifikan antara pengetahuan dengan pemberian ASI Eksklusif di Wilayah Kerja Puskesmas Sigalingging Kabupaten Dairi.

2. Terdapat hubungan yang signifikan antara dukungan suami dengan pemberian ASI Eksklusif di Wilayah Kerja Puskesmas Sigalingging Kabupaten Dairi.

3. Terdapat hubungan yang signifikan antara persiapan fisik dan mental dengan pemberian ASI Ekslusif di Wilayah Kerja Puskesmas Sigalingging Kabupaten Dairi.

4. Terdapat hubungan yang signifikan antara dukungan petugas kesehatan dengan pemberian ASI Eksklusif di Wilayah Kerja Puskesmas Sigalingging Kabupaten Dairi.

\section{SARAN}

1. Diharapkan kepada ibu hendaknya lebih rajin mencari informasi mengenai ASI Eksklusif baik dari buku, majalah, televisi, radio maupun dari petugas kesehatan.

2. Diharapkan kepada ibu agar aktif menghadiri pertemuan tentang masalah kesehatan baik di posyandu, puskesmas maupun fasilitas kesehatan lainnya.

3. Diharapkan kepada ibu aktif membawa bayi ke posyandu baik untuk imunisasi maupun menimbang bayi sebagai sarana informasi dan tanya jawab mengenai ASI Eksklusif sebagai dasar pertumbuhan dan perkembangan bayi.

4. Diharapkan kepada tenaga kesehatan khususnya KIA-KB, GIZI dan Promkes agar aktif melakukan penyuluhan mengenai ASI Eksklusif kepada ibu /suami/ keluarga baik melalui kegiatan kelas ibu hamil, pemberian PMT kepada ibu hamil dan menyusui dalam bentuk ceramah, penyebaran leaflet , brosur dan membuat poster yang menarik mengenai ASI Eksklusif.

5. Diharapkan kepada tenaga kesehatan khususnya KIA-KB, GIZI aktif melakukan evaluasi kepada ibu nifas dan bidan penolong tentang tindakan IMD dan pemberian Kolostrum oleh ibu kepada bayinya.

6. Diharapkan kepada tenaga kesehatan khususnya KIA-KB, GIZI dan Promkes aktif mengikuti pelatihan dan workshop yang diadakan kabupaten maupun propinsi untuk mengbangkan SDM tentang penyuluhan kesehatan ASI Eksklusif. Untuk meningkatkan ASI Eksklusif perlu kerjasama dari aparat pemerintah beserta masyarakat dan petugas kesehatan melalui pemanfaatan dana desa melalui kegiatan pelatihan kader, pemberian transportasi kader agar kader aktif dalam kegiatan kesehatan.

7. Diharapkan kepada kepala desa agar menghimbau masyarakat untuk secara rutin datang ke pelayanan kesehatan khususnya kepada ibu hamil dan ibu menyusui baik untuk menimbang maupun kegiatan imunisasi.

8. Diharapkan kepada kepala desa agar mengundang Tokoh Agama dan Tokoh Masyarakat dalam kegiatan rutin 
pertemuan tingkat desa agar secara bersama sama membahas penyebab rendahnya ASI Eksklusif dan melalui kegiatan tersebut Tenaga kesehatan dapat memberikan penyuluhan / informasi mengenai ASI Eksklusif dan Bahaya MP-ASI dini.

9. Diharapkan peneliti selanjutnya dapat melakukan penelitian lanjutan dalam tehnik dan obyek yang berbeda.

\section{DAFTAR PUSTAKA}

Departemen kesehatan RI. (2011). Konseling Menyusui Untuk Petugas Kesehatan. Jakarta: EGC.

Devi dkk. (2014). Dukungan Keluarga Dan Praktik Pemberian Asi Eksklusif Di Puskesmas Pucang Sewu. FKM UNAIR. http://scholar. google.co.id/scholar?g=dukungan+kel uarga+asi+puskesmas+pucang+sew\&b tng $=\& h l=i d \& a s \_s d t=0 \% 2 C 5 \& a s \_v i s=$ $1(25=04-2017)$

Fatmah. (2014). Teori Penerapan Media Komunikasi Informasi dan Edukasi Gizi. Jakarta: Erlangga.

Hervilia dkk, (2016). Pandangan Sosial Budaya terhadap ASI Eksklusif di wilayah Panarung Palangkaraya. Poltekes Gizi Palangkaraya. http://scholar.

google.co.id/scholar?g=pandangan+so sial+budaya $=$ asi + panarung $\& b \operatorname{tnG}=\& \mathrm{hl}$ $+\mathrm{id} \&$ as_sdt $=0 \% 2 \mathrm{C} 5 \&$ asylo=2016\&as_vis $=1 .(25-04-2014)$

Hidayati, Hajaroh. (2013). Hubungan Sosial Budaya Dengan Pemberian Keberhasilan ASI Eksklusif pada ibu menyusui di Posyandu Wilayah DesaSrigading Sanden Bantul Yogyakarta. STIKes AISYAH. Yogyakarta.

http://scholar.google.co.id/scholar?g=p andangan+sosial+budaya $=$ asi+panarun g\&btnG $=\& h l+i d \& a s \_s d t=0 \% 2 C 5 \&$ asylo=2016\&as_vis $=1 .(25-04-2013)$

Istikhomah dkk. (2014). Gambaran Pengetahuan Ibu menyusui tentang Daun Katuk sebagai Pelancar Asi di BPM Benis Jayanto Ceper Klaten. Jurnal Kebidananan Indonesia. 7,1(2016).http://scholar?Start $=10 \& g=p$ engetahuan+ibu+menyusui+daun+katu $\mathrm{k}+$ produksi+asi\&hl=id\&as_sdt=0,5\&a s_vis=1 (22-04-2017)
Kartika dkk. (2013). Gambaran tingkat Pengetahuan ibu tentang ASI Eksklusif di desa Butuh Kecamatan Tenggaran Kabupaten Semarang. Prosiding seminar nasional \& internasional.vol.2. $2014 . \quad \mathrm{http} / \mathrm{scholar}$. google.co.id/scholar?as_ylo=2013\&g= gambaran+tingkat+pengetahuan+ibu+a si+kabupaten+semarang\&hl=id\&as_sd $\mathrm{t}=0,5$ \&as_vis=1.(25-04-2014)

Indonesia, Kementerian Kesehatan. (2015). Profil Kesehatan Indonesia Tahun 2014. Jakarta: Kemenkes RI.

Kepala Dinas Kesehatan Kabupaten Dairi. (2013). Profil Kesehatan Kabupaten Dairi tahun 2013. Sidikalang: Dinkes Kab.Dairi.

Kepala Dinas Kesehatan Kabupaten Dairi. (2014). Profil Kesehatan Kabupaten Dairi tahun 2015. Sidikalang: Dinkes Kab.Dairi.

Kepala Dinas Kesehatan Kabupaten Dairi. (2015). Profil Kesehatan Kabupaten Dairi tahun 2016. Sidikalang: Dinkes Kab.Dairi.

Keputusan Menteri Kesehtan RI. No 900/Men.Kes/SK/VII/2002. Jakarta: Kemenkes RI.

Khamzah , Siti. (2012). Segudang Keajaiban ASI. Jakarta: Flash Books.

Labbock, M.H. Hudgens, Nickel, N.C.,M.G \& Daniels, J.L. (2013. The Extent thatNoncompliance, Journal of Human Lactation. $29 \quad$ (1) 59-70. http://scholar.google.co.id/scholar?g=t he+extent+non+compliance+journal+o $\mathrm{f}+$ human+lactation\&hl=id\&as_sdt $=0$ \& as_vis $=1 \&$ oi $=$ scholar $+\&$ sa $+x \& v e d=0 a$ hUKEwjRx96mmgJjUAhWKmJQKH ZGPC1kQgQMICDAA.(25-04-2017)

Laanterä, S., Pölkki, T., Ekström, A., Pietilä, Anna-Maija. (2010). Breastfeeding Attitudes of Finnish Parents during Pregnancy. BMC Pregnancy and Childbirth, Vol.10, p.79. http:// scholar.google.co.id/scholar?g=the+ext ent+non+compliance+journal+of+hum an+lactation\&hl=id\&as_sdt=0\&as_vis $=1 \&$ oi $=$ scholar $+\&$ sa $+x \&$ ved $=0$ ahUKE wjRx96mmgJjUAhWKmJQKHZGPC 1kQgQMICDAA. Diakses 25-04-2017 Linda dkk. (2016). Faktor-Faktor Yang Berhubungan Dengan Pemberian Asi Eksklusif Di Wilayah Kerja Puskesmas Bahu KecamatanMalalayang Kota 
Manado. Universitas Sam Ratulangi Manado. FKM. Diambil dari: http://scholar.google.co.id/scholar?hl=i d\&as_sdt $=0,5 \&$ as_ylo $=2016 \&$ as_vis $=$ $1 \& \mathrm{~g}=$ faktor+asi+eksklusif+puskesmas +bahu.(25-04-2014)

Mariyunani,Anik. (2012). Inisiasi Menyusui Dini, ASI Eksklusif dan Manajemen Laktasi. Jakarta: Trans Info Media.

Myrnawaty, dr DR. Prof. Metodologi Penelitian. Jakarta :FIP PRESS.

Pollard, Maria. (2015). ASI Asuhan Berbasis Bukti. Jakarta:EGC.

Prasetyono, Sunar Dwi. (2012). Buku Pintar Asi Eksklusif. Yogyakarta: Diva Press.

Rahman,Abd. (2015). Hubungan Pengetahuan Dan Sikap Suami Dengan Praktek Pemberian ASI Eksklusif Di Puskesmas Managaisaki. Magaisak: jurnal kesehtan Masyarakat. Vol.

\section{5 ,}

No.1.http://scholar.google.co.id/schola $\mathrm{r}$ ?g=puskesmas+managaisaki\&btng $=\&$ hl. $=$ id\&as_sdt $=0 \% 2 \mathrm{c} 5 \&$ as_vis $=1 .(24-$ 04-2017)

Robin, Lim. (2007). Hubungan dukungan suami dengan pemebrian ASI Eksklusif di wilayah kerja Puskesmas Air Tawar Kota Padang Sumatera Barat Tahun 2007. FKM UI.Diambil dari:http://scholar.google.co.id/scholar $? \mathrm{hl}=\mathrm{id} \&$ as_sdt $=0,5 \&$ as_ylo $=2016 \&$ as vis $=1 \& \mathrm{~g}=$ faktor+asi+eksklusif + puskes mas+air+tawar.(25-04-2014

Sudjana, M.a. MSc. Pdf Prof. DR. (2005). Metode Statistika. Jakarta: Tarsito.

Tohotoa, J., Maycock, B., Hauck Y.L., Howat, P., Burns, S., Binns, C.W. (2009). Dads Make A Difference: An Exploratory Study of Paternal Support for Breastfeeding in Perth, Western Australia. International Breastfeeding Journal, Vol.4, p.15. http://scholar.google.co.id/scholar?g=t he+extent+non+compliance+journal+o $\mathrm{f}+$ human+lactation\&hl=id\&as_sdt=0\& as_vis $=1 \&$ oi $=$ scholar $+\&$ sa $+x \& v e d=0 a$ hUKEwjRx96mmgJjUAhWKmJQKH ZGPC1kQgQMICDAA Diakses 7 Maret 2017

Tesfaye dkk. (2012). Factors associated with exclusive breastfeeding practices among mothers in Goba district, southeast Ethiopia: a cross-sectional study.University, Bale

Goba,
Ethiopia.http://scholar.google.co.id/sch olar? $g=$ factor+associated+with+exclus ive+breast+feeding+in+goba\&btnG $=\&$ $\mathrm{hl}=\mathrm{id} \&$ as_sdt $=0 \& 2 \mathrm{C} 5 \& \mathrm{as} \_v i s=1(25-$ 04-2017)

Victor. Dkk. (2016). Knowledge, Attitudes And Determinants Of Exclusive Breastfeeding Practice Among Ghanaian Rural Lactating Mothers. University for Development Studies. http://scholar.google.co.id/scholar?as_ ylo=2016\&g=,AttitudesAnd+determin ants+OfExclusive+breastfeeding+pract ice+among+ghanaian+rural+lactating+ mothers\&hl=id\&as_sdt $=0,5 \&$ as_vis $=1$ (25-04-2017)

Yanuarita, Andri Franc. (2013). Menjadi Teman Pertumbuhan Buah Hati.J awa Tengah: Teranova Book.

Yuliarti, Nurheti. (2015). Keajaiban ASI. Yogyakarta: Andi. 